\title{
Evaluation of energy consumption during the seawater desalination process simulated to the aqueous ternary system $\{\mathrm{NaCl}+\mathrm{KCl}\}_{(\mathrm{aq})}$
}

\author{
Abdelkbir Errougui ${ }^{1}{ }^{(D *}$, Asmaa Benbiyi ${ }^{2}$, and Mohamed El Guendouzi ${ }^{2}$ \\ ${ }^{1}$ Laboratory of Analytical and Molecular Chemistry, \\ ${ }^{2}$ Laboratory of Physical-Chemistry, Catalysis and Environment, \\ Faculty of Sciences Ben M'Sik, Hassan II University of Casablanca, Morocco. \\ (Dhttps://orcid.org/0000-0001-9972-7522
}

\begin{abstract}
Energy consumption is a purely thermodynamic concept very useful in several scientific fields such as desalination, oceanography, biology, geochemistry and environmental processes, as well as in industrial applications. In this investigation, based on a thermodynamic approach, the calculation of energy consumption was evaluated during the desalination of seawater simulated to the aqueous ternary system $\{\mathrm{NaCl}+\mathrm{KCl}\}_{(\text {aq) }}$. The mixing ionic parameters, obtained in our previous work, are used to predict the osmotic and activity coefficients in the aqueous solutions at different salinities ranging from 3.6 up to 72 g. $\mathrm{L}^{-1}$ at $\mathrm{T}=298.15 \mathrm{~K}$ using the ion interaction model. The theoretical energy consumption of desalination was calculated at various salinities and recovery ratios.
\end{abstract}

Keywords: Theoretical energy consumption; Desalination; Ionic interaction model; Osmotic coefficient; Activity coefficient; Sodium chloride; Potassium chloride.

\footnotetext{
*Corresponding author: a_errougui@yahoo.fr
} 


\section{Introduction}

Water is an essential material in our daily life. Worldwide water demand increased substantially over the past decades as results of urbanization, agricultural intensification, population growth, and climate change and the accelerated development of modern industrial techniques [1-3]. To meet the demand for water resources in areas where reserves are insufficient, several countries have resorted to seawater desalination. Many physical methods are used to obtain freshwater from seawater. Those which have had great success today are distillation and reverse osmosis. These techniques are implemented on an industrial scale for large production capacities and have undergone considerable technological developments to make them more competitive. Other techniques such as freezing, electrodialysis or humidification are under development and can only be adapted for low-capacity installations.

Desalination of seawater makes it possible in particular to increase the available freshwater resources, to provide a solution in the event of drought and to cope with situations of shortages and crises [4]. However, seawater desalination remains an energy-intensive activity that consumes lot of energy. The optimization and reduction of the specific energy consumption of this process is a major issue, in order to be able to satisfy the increasing demand with better quality at lower cost. Indeed, based on a thermodynamic approach the theoretical energy consumption (TEC) was developed for the desalination of marine water simulated with the majority electrolyte of $\mathrm{NaCl}$ in $\mathrm{KCl}$ aqueous solutions $[5,6]$ at $\mathrm{T}=25{ }^{\circ} \mathrm{C}$, using ionic interaction model.

\section{Theoretical approach}

\subsection{Ion interaction model}

The thermodynamic properties of polyelectrolyte solutions were determined using the ion interaction model [7-9]. This model requires parameters estimated from common-ion solutions in order to characterize binary interactions among different ions of the same sign, and ternary interactions between different ions (not all of the same sign) in a mixed-electrolyte solution. The osmotic coefficient of a mixed solution of $\mathrm{NaCl}$ and $\mathrm{KCl}$ having a common anion is given by:

$$
\begin{aligned}
\phi & =1+f^{\phi}+y I\left[B_{\mathrm{NaCl}}^{\phi}+I C_{\mathrm{NaCl}}^{\phi}\right] \\
& +(1-y) I\left[B_{\mathrm{KCl}}^{\phi}+I C_{\mathrm{KCl}}^{\phi}\right] \\
& +y(1-y) I\left[\theta_{\mathrm{NaK}}+I \psi_{\mathrm{NaKCl}}\right]
\end{aligned}
$$

where $I$ is the ionic strength of the common ion, $\theta_{\mathrm{NaK}}$ is a binary mixing parameter involving unlike ions of the same sign, and $\psi_{\mathrm{NaKCl}}$ is a ternary mixing parameter for two unlike ions of the same sign with a third ion of opposite sign.
The second virial coefficient $\mathrm{B}^{\phi}$ for electrolyte $1-1$ is defined as

$$
B^{\phi}=\beta^{(0)}+\beta^{(1)} \exp \left(-\alpha I^{\frac{1}{2}}\right)
$$

$\beta^{(0)}, \beta^{(1)}$, and $C^{\phi}$ are ion interaction parameters which are functions of temperature and pressure, where $\alpha=2 \mathrm{~mol}^{-1 / 2} \cdot \mathrm{Kg}^{1 / 2}$.

The activity coefficients $\gamma_{\mathrm{NaCl}}$ of $\mathrm{NaCl}$ and $\gamma_{\mathrm{KCl}}$ of $\mathrm{KCl}$ in a common anion mixture of $\{\mathrm{yNaCl}+(1-\mathrm{y}) \mathrm{KCl}\}_{(\mathrm{aq})}$ are given by Pitzer's model as

$$
\begin{aligned}
\ln \gamma_{\mathrm{NaCl}} & =f^{\gamma}+(1+y) I\left[B_{\mathrm{NaCl}}+I C_{\mathrm{NaCl}}\right] \\
& +(1-y) I\left[B_{\mathrm{KCl}}+I C_{K C l}\right] \\
& +y I^{2}\left[B_{\mathrm{NaCl}}^{\prime}+C_{\mathrm{NaCl}}\right] \\
& +(1-y) I^{2}\left[B_{\mathrm{KCl}}^{\prime}+C_{K C l}\right] \\
& +(1+y) I \theta_{\mathrm{NaK}}+\frac{1}{2}(1-y)(1+y) I^{2} \psi_{\mathrm{NaKCl}},
\end{aligned}
$$

and

$$
\begin{aligned}
\ln \gamma_{K C l} & =f^{\gamma}+y I\left[B_{\mathrm{NaCl}}+I C_{\mathrm{NaCl}}\right] \\
& +(2-y) I\left[B_{\mathrm{KCl}}+I C_{K C l}\right] \\
& +y I^{2}\left[B_{\mathrm{NaCl}}^{\prime}+C_{\mathrm{NaCl}}\right] \\
& +(1-y) I^{2}\left[B_{\mathrm{KCl}}^{\prime}+C_{K C l}^{\prime}\right] \\
& +y I \theta_{\mathrm{NaK}}+\frac{1}{2} y(2-y) I^{2} \psi_{\mathrm{NaKCl}},
\end{aligned}
$$

The coefficients $B_{M X}$ and $B_{M X}^{\prime}$ for each electrolyte is defined as

$$
\begin{aligned}
& B_{M X}=\beta^{((0)}+\left(2 \beta^{(1)} / \alpha^{2} I\right)\left[1-\left(1+\alpha I^{1 / 2}\right) \exp \left(-\alpha I^{1 / 2}\right)\right],(5) \\
& B_{M X}^{\prime}=\left(\beta^{(1)} / \alpha^{2} I^{2}\right)\left[-1+\left(1+\alpha I^{1 / 2}+1 / 2 \alpha^{2} I\right) \exp \left(-\alpha I^{1 / 2}\right)\right],
\end{aligned}
$$

From the osmotic coefficients determined from the experimental water activities of the studied mixture at different ionic-strength fractions, it is possible to estimate the unknown Pitzer mixing ionic $\theta_{\mathrm{NaMg}}$ and $\psi_{\mathrm{NaMgCl}}$ by a graphical procedure. This procedure defines the quantity $\Delta \phi$ as the difference between the experimental values, $\phi_{\text {exp }}$, and the values calculated from Eq. (6), $\phi_{\text {cal }}$.

\subsection{Theoretical energy consumption approach of seawater desalination}

The electrolyte solution with an amount of salts MX follows that $\quad \mathrm{M}_{v+} \mathrm{X}_{\mathrm{v}-} \leftrightarrow \mathrm{v}^{+} \mathrm{M}^{\mathrm{z}+}+\mathrm{v}^{-} \mathrm{X}^{\mathrm{z}-}$.

The total Gibbs energy of the electrolyte solution is

$$
\mathrm{G}=\sum_{\mathrm{i}=1}^{\mathrm{N}} \mathrm{n}_{\mathrm{MX}, \mathrm{i}} \mu_{\mathrm{MX}, \mathrm{i}}+\mathrm{n}_{\mathrm{s}} \mu_{\mathrm{s}}
$$

Where, $i, n_{M X}$ and $n_{s}$ represent the species of salts, the number of moles of each salt and the number of moles of solvent in electrolyte solution, respectively [10]. 
The chemical potential of the solvent $\mu_{s}$ can be calculated by the following equation

$$
\mu_{s}=\mu_{s}^{0}+R T \ln a_{s}=\mu_{s}^{0}-R T \frac{v m_{M X} M_{s}}{1000} \phi,
$$

Where, $\mu_{s}^{0}$ is the chemical potential of the solvent (water) at temperature $\mathrm{T}$ and pressure $\mathrm{P}, \mathrm{a}_{\mathrm{s}}, \mathrm{M}_{\mathrm{s}}, \phi$ represents the activity, molar mass, osmotic coefficients of the solvent, respectively.

Then Eq. (7) can be rewritten as

$$
\begin{aligned}
G= & \sum\left\{n_{M X} \mu_{M X}^{0}+v n_{M X} R T \ln \left(\gamma_{M X} m_{M X}\left(v_{+}^{v+} v_{-}^{\nu-}\right)^{1 / v}\right\}\right. \\
& +n_{s}\left(\mu_{s}^{0}-R T \frac{v m_{M X} M_{s}}{1000} \phi\right),
\end{aligned}
$$

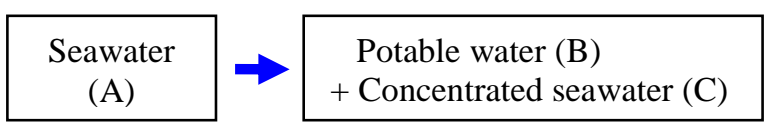

The TEC for the global process of seawater desalination can be calculated by the following equation

$$
\Delta G=G_{B}+G_{C}-G_{A}
$$

The calculation of the TEC of seawater desalination is given by the Eq.(11) as reported by Qian et al. [11]:

$$
\begin{aligned}
\Delta G & =\left\{\begin{array}{c}
\sum\left\{v n_{M X} R T \ln \left(\gamma_{M X} m_{M X}\left(v_{+}^{v+} v_{-}^{v-}\right)^{1 / v}\right\}\right. \\
-n_{s, B} R T \frac{v m_{M X} M_{s}}{1000} \phi
\end{array}\right\}_{B} \\
& +\left\{\begin{array}{c}
\sum\left\{\frac{v\left(n_{M X, A}-\eta n_{M X, B}\right)}{1-\eta} R T \ln \left(\gamma_{M X} m_{M X}\left(v_{+}^{v+} v_{-}^{v-}\right)^{1 / v}\right\}\right. \\
-n_{s, B} \frac{1-\eta}{\eta} R T \frac{v m_{M X} M_{s}}{1000} \phi
\end{array}\right\}_{C} \\
& +\left\{\begin{array}{c}
\sum\left\{v n_{M X, A} R T \ln \left(\gamma_{M X} m_{M X}\left(v_{+}^{v+} v_{-}^{v-}\right)^{1 / v}\right\}\right. \\
-\frac{n_{s, B}}{\eta} R T \frac{v m_{M X} M_{s}}{1000} \phi
\end{array}\right\}
\end{aligned}
$$

Where, $n_{M X, A}, n_{M X, B}$, and $\eta$ represent the number of moles of each salt in the input seawater and potable water, and recovery ratio, respectively. $n_{s, B}$ stands for the molar number of water $\left(n_{s, B}=1000 / M_{s} \mathrm{~mol}\right.$, where $M_{s}$ is the molar mass of water).

\section{Results and discussion}

\subsection{Osmotic and activity coefficients}

The osmotic and activity coefficients of $\mathrm{NaCl}_{(\mathrm{aq})}$ and $\mathrm{KCl}_{(\mathrm{aq})}$ in ternary system $\{\mathrm{NaCl}+\mathrm{KCl}\}_{(\mathrm{aq})}$ are calculated using our ionic mixing parameters of Pitzer's equations [12,13] and listed in Table 1 . These coefficients were presented as a function of salinity and shown in Figures 1, and 2.
Table 1. Ionic interaction parameters for $\mathrm{NaCl}, \mathrm{KCl}$, and their mixtures at $298.15 \mathrm{~K}$

\begin{tabular}{ccccc}
\hline System & $\beta^{(0)}$ & $\beta^{(1)}$ & $\mathrm{C}^{\phi}$ & Ref \\
\hline $\mathrm{NaCl}_{(\mathrm{aq})}$ & 0.0738 & 0.2712 & 0.00167 & {$[12]$} \\
\hline $\mathrm{KCl}_{(\mathrm{aq})}$ & 0.04631 & 0.2157 & 0.00003 & {$[12]$} \\
\hline $\multirow{2}{*}{\mathrm{NaCl}+\mathrm{KCl}}_{(\mathrm{aq})}$ & $\theta_{\mathrm{NaK}}$ & $\psi_{\mathrm{NaKCl}}$ & \\
& -0.015 & 0.0035 & {$[13]$} \\
\hline
\end{tabular}

Table 2. Osmotic and activity coefficients calculated at different salinities for the ternary system $\{\mathrm{NaCl}+\mathrm{KCl}\}(\mathrm{aq})$ at $298.15 \mathrm{~K}$

\begin{tabular}{ccccc}
\hline $\begin{array}{c}\text { Salinity } \\
\left(\mathrm{g} . \mathrm{L}^{-1}\right)\end{array}$ & $\begin{array}{c}\text { Ionic } \\
\text { strength }(I)\end{array}$ & $\phi_{\text {cal }}$ & $\gamma_{\mathrm{NaCl}}$ & $\gamma_{\mathrm{KCl}}$ \\
\hline 3.6 & 0.0493 & 0.9434 & 0.8209 & 0.8176 \\
18 & 0.2463 & 0.9207 & 0.7183 & 0.7059 \\
36 & 0.4926 & 0.9195 & 0.6787 & 0.6575 \\
54 & 0.7389 & 0.9245 & 0.6609 & 0.6321 \\
72 & 0.9852 & 0.9322 & 0.6526 & 0.6167 \\
\hline
\end{tabular}

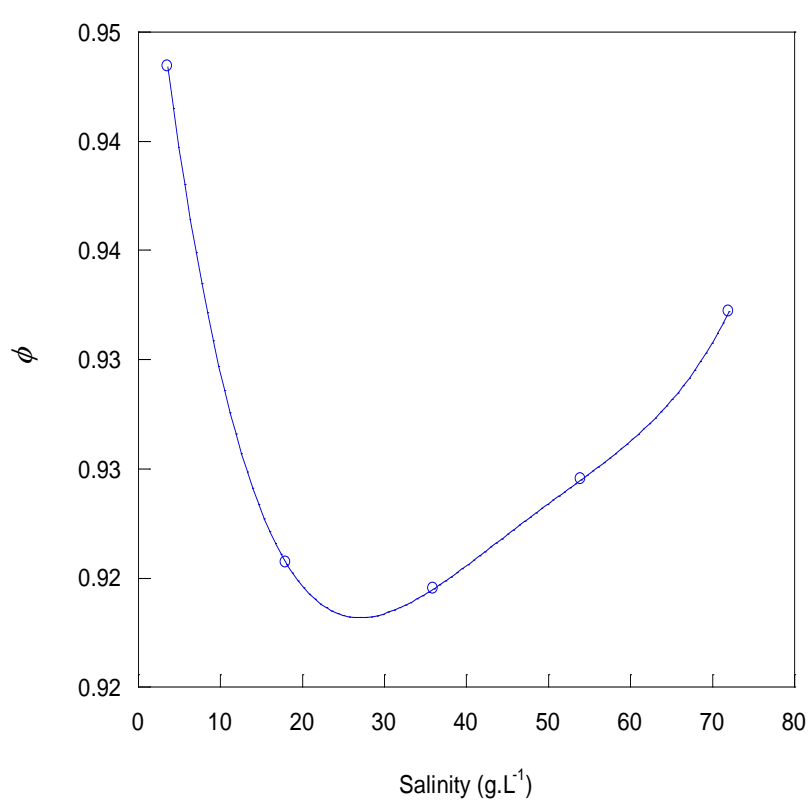

Figure 1. Osmotic coefficients $\phi$ as a function of salinity

According to the figures 1 and 2, the activity coefficients decrease when the salinity of the solution rises. This behaviour is mainly due to the interactions involved between the molecules (water) and ions in aqueous solutions. Indeed, the properties of this system depend on the interactions ion-ion, ion-water, and water-water. These interactions are influenced by the hydration phenomena of the electrolytes in aqueous solutions that have a consequence on the water activity behaviour [14-16]. 


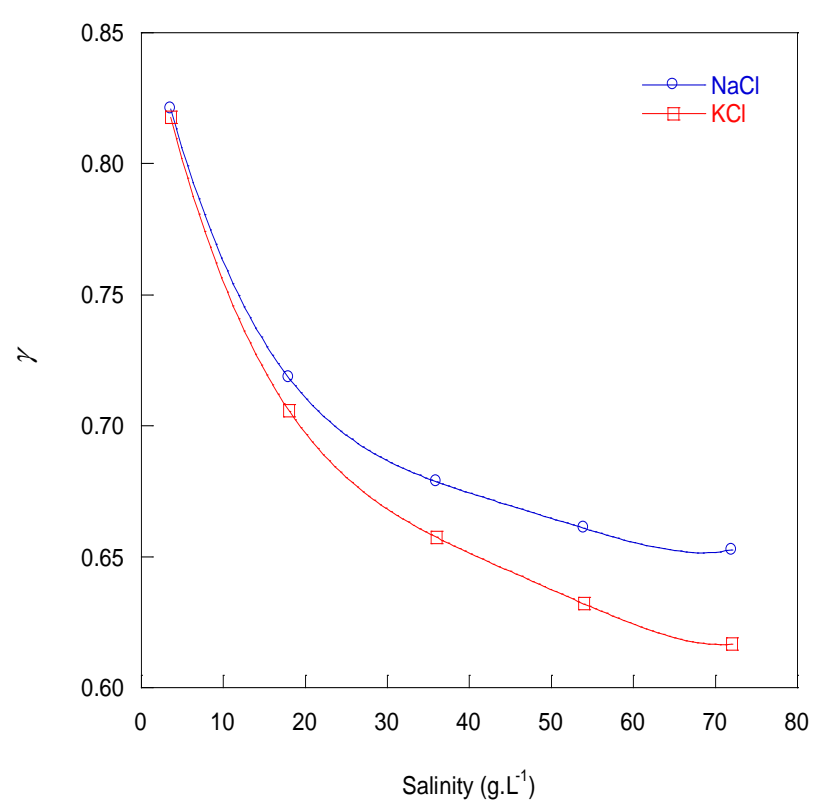

Figure 2. Activity coefficients $\gamma$ as a function of salinity

\subsection{Evaluation of Theoretical energy consumption}

The thermodynamic theory tells that more TEC is needed owing to the negative deviation when the osmotic and activity coefficients of salts are less than unit in the electrolyte solutions. As shown in Fig. 3, the TEC increases slightly with increasing salinity and recovery ratio. However, when the recovery ratio reaches $40 \%$, the TEC increases promptly. This behavior could be explained by the negative deviation of osmotic and activity coefficients. That's due to the non-ideality of the marine environment which is attributed to the formation of hydrated complexes leading to a decrease in the number of unbound water molecules.

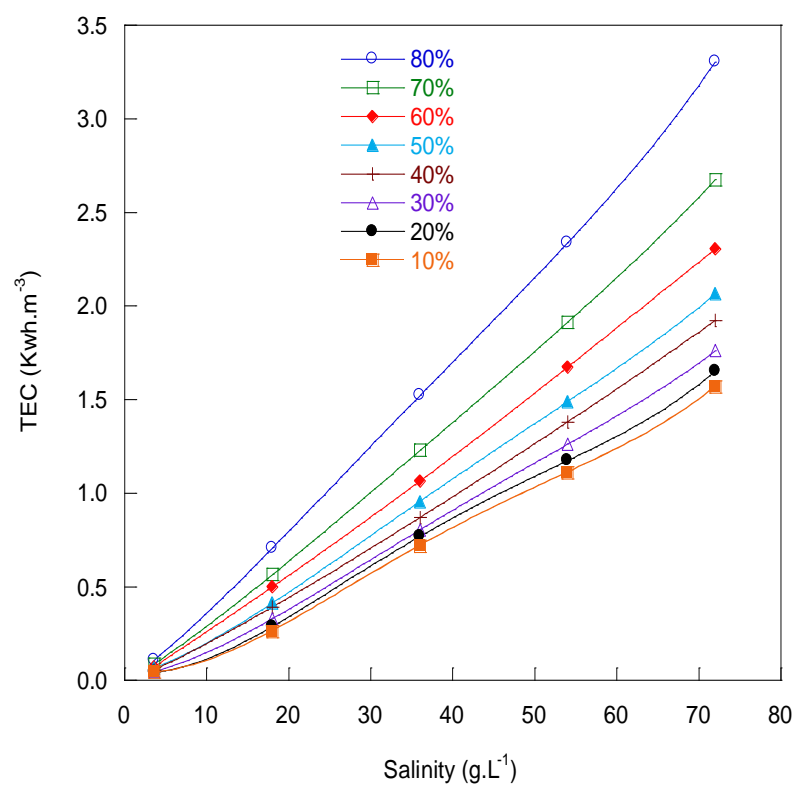

Figure 3. Theoretical energy consumption as a function of salinity at various recovery ratios $(\eta)$

\section{Conclusion}

In this investigation, the thermodynamic properties of seawater simulated to the ternary system $\{\mathrm{NaCl}+\mathrm{KCl}\}$ (aq) were determined using the formalism developed on the basis of Pitzer's ionic interaction model.

The theoretical energy consumptions were estimated during the desalination process at various salinities in the mixture of chlorides sodium and potassium. The TEC rises with the salinity of marine water increases. The obtained results strongly depend on the salinity of marine water and the recovery ratio.

\section{References}

[1] X. Ji, E. Kang, R. Chen, W. Zhao, S. Xiao, B. Jin, Analysis of Water Resources Supply and Demand and Security of Water Resources Development in Irrigation Regions of the Middle Reaches of the Heihe River Basin, Northwest China, Agric. Sci. China5 (2006) 130-140.

[2] I.E.M. de Graaf, L.P.H. Van Beek, Y. Wada, M.F.P. Bierkens, Dynamic attribution of global water demand to surface water and groundwater resources: Effects of abstractions and return flows on river discharges, Adv. Water Resour.64 (2014) 21-33.

[3] Y. Shena, T. Okib, S. Kanaec, N. Hanasakid, N. Utsumib, and M. Kiguchib, Projection of future world water resources under SRES scenarios: an integrated assessment, Hydrol. Sc. J. 59 (2014) 1775-1793.

[4] E. McDonald, B. Coldrick, and W. Christensen, The Green Frog and Desalination: A Nyungar Metaphor for the (Mis-) Management of Water Resources, Swan Coastal Plain, Western Australia, Oceania, 78 (2008) 62-75.

[5] F. J. Milleroa, R. Feistelb, D. G. Wrightc, T.J. McDougall, The composition of Standard Seawater and the definition of the Reference-Composition Salinity Scale, Deep-Sea Res. I, 55 (2008) 50-72.

[6] K. H. Mistry, H. A. Hunter, J. H. Lienhard V, Effect of composition and nonideal solution behavior on desalination calculations formixed electrolyte solutions with comparison to seawater. Desalination, 318 (2013) 34-47.

[7] K.S. Pitzer, Thermodynamics of electrolytes. I. Theoretical basis and general equations, J. Phys. Chem. 77 (1973) 268-277.

[8] K.S. Pitzer, G. Mayorga, Thermodynamics of electrolytes. II. Activity and osmotic coefficients for strong electrolytes with one or both ions univalent, J. Phys. Chem. 77 (1973) 2300-2307.

[9] K.S. Pitzer, J. J. Kim, Thermodynamics of Electrolytes.: IV. Activity and Osmotic Coefficients for Mixed Electrolytes, J. Am. Chem. Soc. 96 (1974) 5701-5707.

[10] J. M. Prausnitz, R. N. Lichtenthaler, E. C. de Azevedo, Molecular Thermodynamics of FluidPhase Equilibria, Prentice Hall PTR, New Jersey, 1999. 
[11] H. Qian, Z. Zhou, L. Zhang, F. Wu, Q. Zhang, Z. Zhang, Thermodynamic analysis on the theoretical energy consumption of seawater desalination, Desalination. 320 (2013) 73-79.

[12] M. El Guendouzi,A. Dinane, A. Mounir, Water activities, osmotic and activity coefficients in aqueous chloride solutions at $\mathrm{T}=298.15 \mathrm{~K}$ by the hygrometric method, J. Chem. Thermodyn. 33 (2001) 1059-1072.

[13] A. Dinane, M. El Guendouzi, A. Mounir, Hygrometric determination of water activities, osmotic and activity coefficients of $(\mathrm{NaCl}+\mathrm{KCl})_{(\mathrm{aq})}$ at $\mathrm{T}=298.15 \mathrm{~K}$, J. Chem. Thermodyn. 34 (2002) 423-441.

[14] A. Errougui, M. El Guendouzi, Thermodynamic properties of ternary aqueous solutions of $\left\{\mathrm{Li} / \mathrm{Cl} / \mathrm{NO}_{3} / \mathrm{SO}_{4}\right\}$ (aq) mixtures at $\mathrm{T}=298.15 \mathrm{~K}$, Fluid Phase Equilibr. 266 (2008) 76-83.

[15] A. Errougui, M. El Guendouzi, Thermodynamic properties of ternary aqueous mixtures of $\left\{\mathrm{yMgCl}_{2}+(1-\mathrm{y}) \mathrm{Mg}\left(\mathrm{NO}_{3}\right)_{2}\right\}(\mathrm{aq})$ at $\mathrm{T}=298.15 \mathrm{~K}$, Calphad 30 (2006) 260-265.

[16] A. Errougui, M. Talbi, M. El Kouali, Molecular dynamics simulations of Lithium Fluoride aqueous solutions: Effects of ion concentration on the structural and dynamical properties at $\mathrm{T}=300 \mathrm{~K}$. Egyp. J. Chem. Accepted Manuscript. DOI: 10.21608/ejchem.2021.67302.3453. 